SHORT REPORT

\title{
Prevalence of wife beating in Jordanian refugee camps: reports by men and women
}

\author{
Marwan Khawaja, Rana Barazi
}

J Epidemiol Community Health 2005;59:840-841. doi: 10.1136/jech.2004.031625

W ife beating, the most widespread form of domestic violence, has adverse consequences on the health and wellbeing of women and is a major cause of disability and death in many countries. ${ }^{1}$ In the past few years, it has been widely reported in developing countries' contexts, ${ }^{2}$ where patriarchal family norms are common. ${ }^{3}$ In the Middle East, patriarchal gender relations reinforced by traditional cultural, legal, and perhaps religious legacies may have directly or indirectly influenced the persistence of violence against women. In fact, intimate partner violence is not considered a criminal act in many Arab countries. Available studies provide only limited insight into the prevalence of domestic violence in a patriarchal context. Furthermore, most previous studies of wife beating from developing countries focused on female respondents, thus neglecting men, the perpetrators of violence.

Using data from independent samples of married men and women, this study investigated the prevalence of wife beating in the Palestinian refugee camps of Jordan. Specifically, the study aimed to examine the similarity between men's self reports of violence and women's reports of being subjected to domestic violence. The focus was on lifetime physical domestic violence against women, but estimates of current (past year) beating as well as injuries resulting from beating were also described.

\section{METHODS}

This exploratory study used data from the recently completed living conditions survey of Jordan's refugee camps. This was a cross sectional survey of 2590 households selected randomly from 12 refugee camps using a sampling frame provided by Jordan's Department of Statistics. Some of the camps housed refugees displaced as a result of the 1967 war, others included refugees from the 1948-49 Arab-Israeli war. The instrument consisted of three questionnaires: one for the household, one for a randomly selected adult aged 15+ years from each household, and the third for all ever-married women. The data pertaining to wife beating were obtained by face to face interviews with randomly selected adults (adult questionnaire). The study was approved (including an ethical review) by Yarmouk University and the government of Jordan. Fieldwork took place in the spring and summer of 1999, with an overall response rate of $95 \%$. Our original sample was reduced because of the eligibility criteria used for answering the domestic violence questions: currently married, living with spouse, and privacy during the interview. Of the total sample of 801 married adults, 395 persons (262 women and 133 men) were included in the study. There was remarkable similarity between our sample and the original one in terms of demographic and socioeconomic characteristics. However, the selected sample was slightly younger (mean age 37.5 ) than the original (mean age 40), and hence included better educated respondents (29.8\% compared with $25.8 \%$ with secondary education).

We asked married women whether they had experienced specific acts of violence, including being slapped, grabbed, shoved, kicked, hit with fists, having harmful things thrown at them, and being choked by their husbands. Eligible men were asked if they had carried out any of these acts against their wives. Women answering in the affirmative for any of the beating items were then asked if they had been beaten by their husbands during the past year. Those who were beaten in the past year were then asked whether they suffered any of the following types of injuries: bruises; cuts, scratches, or burns; fractures or broken bones; miscarriage; or other injuries. Men were asked the same questions concerning beating in the past year of their wives, and about injuries suffered by their wives as a result of beating. Given the exploratory nature of this brief report, we only included descriptive statistics although $\chi^{2}$ tests were used to examine associations between sex and the outcome variables.

\section{RESULTS}

The prevalence rate of lifetime beating was $44.7 \%$, with men reporting higher overall prevalence $(48.9 \%)$ than women $(42.5 \%)$. As table 1 shows slapping was the most common $(36.0 \%)$ beating behaviour, followed by pushing, grabbing or shoving $(23.5 \%)$, and other unspecified acts of violence $(22.9 \%)$. Lower prevalence rates were reported for kicking or hitting with the fists $(12.6 \%)$, throwing harmful objects

Table 1 Lifetime wife beating behaviour reported by currently married men and women, Jordan refugee camps

\begin{tabular}{|c|c|c|c|c|c|c|c|}
\hline \multirow[b]{2}{*}{ Behaviour } & \multicolumn{2}{|l|}{ Men } & \multicolumn{2}{|l|}{ Women } & \multirow[b]{2}{*}{ p Value* } & \multicolumn{2}{|c|}{ Total sample } \\
\hline & $\mathrm{N}(\%)$ & $95 \% \mathrm{Cl}$ & $\mathbf{N}(\%)$ & $95 \% \mathrm{Cl}$ & & $\mathrm{N}(\%)$ & $95 \% \mathrm{Cl}$ \\
\hline Slapped her & $54(40.7)$ & 32.2 to 49.5 & 88 (33.7) & 27.9 to 39.7 & 0.139 & $142(36.0)$ & 31.3 to 41.0 \\
\hline Was violent toward her & 37 (27.5) & 20.4 to 36.3 & $54(20.6)$ & 15.9 to 26.0 & 0.089 & $91(22.9)$ & 19.0 to 27.6 \\
\hline Pushed, grabbed, or shoved her & $35(26.6)$ & 19.1 to 34.7 & $57(22.0)$ & 16.9 to 27.2 & 0.291 & $92(23.5)$ & 19.3 to 27.8 \\
\hline Kicked or hit her with fists & $12(9.4)$ & 4.7 to 15.2 & 37 (14.2) & 10.1 to 18.9 & 0.149 & 49 (12.6) & 9.3 to 16.1 \\
\hline Threw things at her & $10(7.1)$ & 3.7 to 13.4 & 33 (12.7) & 8.8 to 17.2 & 0.079 & $43(10.8)$ & 8.0 to 14.4 \\
\hline Hit her with an object & $7(4.9)$ & 2.1 to 10.5 & $21(8.1)$ & 5.0 to 12.0 & 0.309 & $28(7.0)$ & 4.8 to 10.1 \\
\hline Choked her & $3(2.4)$ & 0.5 to 6.5 & $9(3.5)$ & 1.6 to 6.4 & 0.522 & $12(3.1)$ & 1.6 to 5.3 \\
\hline At least one behaviour reported & $65(48.9)$ & 40.1 to 57.7 & $111(42.5)$ & 36.3 to 48.6 & 0.170 & $176(44.7)$ & 39.6 to 49.6 \\
\hline
\end{tabular}




\section{Policy implications}

Although reports by men, the perpetrators of violence, may yield similar overall prevalence estimates as those of women, caution should be taken in studies investigating injuries and specific acts of violence.

(10.8\%), hitting with hurtful objects (7.0), and choking (3.1\%). Remarkably, the prevalence rates were strikingly similar between men and women across all behaviours. However, there was a clear sex specific pattern of reporting, with women slightly more likely than men to report the more serious behaviours such as kicking, throwing harmful objects, and choking. Conversely, men were slightly more likely than women to report less severe forms of physical violence including slapping, pushing, and shoving.

Prevalence estimates for past year beating were much lower, and $17.4 \%$ of the respondents experienced beating at least once in the past year overall. Unlike lifetime beating, estimates of past year beating were also slightly different for men and women. While $19.2 \%$ of women reported being beaten during the past year, $13.7 \%$ of men reported that they beat their wives during the same period. However, $\chi^{2}$ test showed no statistical differences $(p=0.176)$ by sex. Similar trends were shown for beating behaviour during pregnancy: $16.6 \%$ of women and $9.8 \%$ of men reported such behaviour.

Results showed that $8.4 \%$ of all respondents reported that women suffered from any type of physical injury as a result of beating. Here, significantly more women (10.4\%) reported wives' injury than men (3.8\%). Among all respondents, 3.7\% reported bruises, $3.4 \%$ reported cuts, scratches or burns, and $2.3 \%$ reported miscarriages.

\section{DISCUSSION}

The overall prevalence of lifetime beating reported here was quite high $(44.7 \%)$ in comparative perspective, but corroborates with a previous study conducted in a similar context. ${ }^{4}$ Our findings, based on independent reporting by men and women, were also consistent with a recent study of married couples in Lebanon, showing remarkably similar rates of lifetime wife beating by sex. ${ }^{5}$ The similarity in reporting reflects the fact that domestic violence may not be considered as taboo in this context. However, sex specific patterns of reporting were evident, with women slightly more likely than men to report the more severe behaviours such as kicking or choking. Furthermore, women were more likely than men to

\section{What this paper adds}

Reporting of wife beating by independent samples of men and women. Sex specific patterns of reporting were evident, with women slightly more likely than men to report the more serious behaviours such as kicking or choking. Furthermore, women were more likely than men to report current-past year-beating, violence during pregnancy, or injuries.

report current-past year-wife beating, violence during pregnancy, and injuries. A number of methodological limitations emerged during analysis, including the cross section design, small sample size, descriptive analytical methods, the emphasis on physical violence, and the inclusion of only camp residents. These clearly limit our ability to generalise the findings to other disadvantaged populations. However, one important implication of our findings can be drawn: although reports by men, the perpetrators of violence, may yield similar overall prevalence estimates of wife beating as those of women, caution should be taken in studies investigating injuries and severe forms of violence based solely on men's reports.

\section{Authors' affiliations}

M Khawaja, R Barazi, Centre for Research on Population and Health, American University of Beirut, Faculty of Health Sciences, Beirut, Lebanon

Funding: data collection for this study was supported in part by a grant from the government of Norway.

Conflicts of interest: none.

Correspondence to: Dr M Khawaja, Centre for Research on Population and Health, American University of Beirut, Faculty of Health Sciences, Beirut, Lebanon; mk36@aub.edu.lb

\section{REFERENCES}

1 Campbell JC. Health consequences of intimate partner violence. Lancet 2002;359:1331-6.

2 WHO. World report on violence and health, In: Krug EG, Dahlberg LL, Mercy JA, et al, eds. Geneva: World Health Organisation, 2002.

3 Jejeebhoy SJ. Wife beating in rural India: A husband's right? Evidence from survey data. Econ Polit Wkly 1998;33:855-62.

4 Haj-Yahia MM, Baerwald P. Wife abuse and its psychological consequences as revealed by the first Palestinian national survey on violence against women. J Fam Psychol 1999;13:642-62.

5 Khawaja M, Tewtel-Salem M. Agreement between husband and wife reports of domestic violence: evidence from poor refugee communities in Lebanon. Int J Epidemiol 2003;33:526-33. 